\title{
Coproduce conservation technology with conservation decisionmakers and practitioners to increase its impact
}

Jacob Malcom ${ }^{1,2}$, Michael Evans ${ }^{1,2}$, Jessica Norriss ${ }^{3}$, Victoria Foster ${ }^{4}$, and Matthew Moskwik ${ }^{4}$

${ }^{1}$ Center for Conservation Innovation, Defenders of Wildlife, Washington DC 20036

${ }^{2}$ Environmental Science and Policy Department, George Mason University, Fairfax VA 22030

${ }^{3}$ Environmental Policy Innovation Center, 777 6th St. NW, 11th Floor, Washington, D.C. 20001

${ }^{4}$ U.S. Fish and Wildlife Service, Ecological Services Program, Falls Church, VA 22041-3803

Keywords: conservation technology, coproduction, Endangered Species Act, law, policy, scalability, software

Word count: 5,615

Number of references: 34

Number of figures: 1

Number of tables: 1 


\begin{abstract}
Addressing the biodiversity crisis will mean developing and adopting new resources and methods that effectively improve public conservation efforts. Technologies have a long track record of increasing the efficiency of carrying out time-consuming tasks or even making new feats possible, and if applied thoughtfully, can serve as a key means of strengthening conservation outcomes. Yet technology development sometimes proceeds without clear mechanisms for application and scaling, or key adopters like government agencies are not able to use the technologies. To overcome these discrepancies, we recommend the use of a coproduction model of conservation technology development that starts from detailed knowledge of conservation laws, regulations, policies, and their implementation; identifies choke points in those processes amenable to technological solutions; and then develops those solutions while integrating existing users and needs. To illustrate the model, we describe three tools recently developed to help improve the efficiency and effectiveness of implementing the U.S. Endangered Species Act. We also highlight several outstanding questions and challenges that the broad conservation technology and policy communities may help address.
\end{abstract}




\section{Introduction}

Global and regional science syntheses highlight the dire status and trends of biodiversity conservation from global to local scales. For one such report, hundreds of scientists integrated the results from $>15,000$ studies to produce the 2019 global assessment from the Intergovernmental Science-Policy Platform on Biodiversity and Ecosystem Services (IPBES). This report produced several key takeaways:

- About 1 million species at risk of extinction now and in coming decades;

- Widespread population declines for species around the world;

- Conversion of huge swaths of terrestrial ( $75 \%)$ and marine ( $66 \%)$ ecosystems by humans; and

- The concomitant decline of ecosystem services on which humans depend (IPBES 2019).

The 2020 report on progress toward the Aichi Targets from the Convention on Biological Diversity (CBD; Secretariat of the Convention on Biological Diversity 2020) as well as the national reports to CBD (e.g., Palau, 2019; Germany, 2020; Kenya, 2021) and other major reports (e.g., WWF, 2020) further emphasize the degree of the challenge that we face. In short, the science is clear about the depth and breadth of the biodiversity crisis, and that addressing the crisis will require transformative, systemic changes (IPBES, 2019; Diaz et al., 2020; Pörtner et al., 2021).

New technologies can be part of the solution to the biodiversity crisis: they can both improve the efficiency of carrying out conservation and enable conservation actions that are otherwise infeasible. For example, hardware technologies have been an essential part of preventing and responding to poaching (Dinerstein, 2018), surveying populations (Lahoz-Monfort \& Magrath, 2021), and reducing the impacts of development such as wind power (McClure et al. 2018). Software, from day-to-day tools like ArcGIS (Esri, 2021) and conservation planning tools like Marxan (Marxan, 2020), Global Forest Watch (Global Forest Watch, 2021), SMART (SMART, 2021) and others, have made it easy to calculate complex spatial statistics or prioritization landscapes that were previously not possible or commonplace. A recent survey of conservation technologists describes the broad scope of the field (Speaker et al., 2021) These technologies were developed with a clear need in mind and have slowly but steadily grown into widespread use, fundamentally changing "business as usual" and showing how new technologies can drive transformative change in conservation.

One possible approach to expanding the use of conservation technology is trying to replicate the "If you build it, they will come" approach of the examples above, an approach is often characteristic of technology start-ups. However, the authors have observed two general challenges that conservation technologies face. First, we have observed technologies that are developed with a vague sense of being "for conservation" but without a clear connection to the structures - governmental or otherwise - that make conservation change happen. For example, one of the co-authors (MJE), while presenting a conservation tool at a Google 
Geo4Good conference, noted that the greatest number of questions from participants were generated when discussing that the tool was being considered for use by a federal agency. This interest in agency adoption and implementation highlights the novelty and importance of this phase of the tech development process, yet a lack of knowledge from developers on how to bridge the adoption gap. Second, we have observed technologies that are developed to address certain conservation policies, only to find that the governmental agency responsible for the policy's implementation is not equipped to adopt the technology (technologically or policy-wise). For example, a common challenge for the private sector selling to the government is that information technology policies are too restrictive, or purchasing and contracting processes are too challenging to effectively navigate. Regardless of the source of the gap between technological capabilities and application, there is a key challenge to overcome in the coming years if necessary changes are to be implemented and technology is to play a significant role in promoting conservation.

Here we outline an approach that we have found very effective at closing the gap between technology development and adoption for conservation. The key challenge we seek to address is how to accelerate and "scale up" the adoption of new conservation technologies as quickly and as widely as possible and avoid some of the preventable challenges. First, we describe several core advantages of the approach, then describe four steps in the process. Next, we describe three case studies - one intragovernmental, one outside of government, and one a public-private partnership. Last, we close out with a brief discussion of open questions of conservation technology development that, when answered, are expected to further improve the process.

\section{Coproducing conservation technology with decision makers}

We have found that integrating existing laws and policies with new technologies from the start of tool design and through implementation is a particularly effective approach to bridging the technology-adoption gap. This is accomplished through collaboration - among technology developers, policy experts, and practitioners who will use the technology (end-users) - to identify the goal and the approach to addressing the goal. This is a specific application of "coproduction," a concept that is well-founded and articulated in conservation science (e.g., Beier et al., 2016; Turnhout et al., 2020), yet appears to be relatively rare or overlooked for conservation technology application. Several key elements highlight why coproduction with governmental decision makers is a strong approach for conservation technology development:

- Conservation laws and policies are established social norms. Laws and policies are formalized articulation of society's normative values. For example, the U.S. Endangered Species Act (ESA) is a national statement that the United States values wildlife and their habitat and will work to ensure they are conserved for future generations. When we build technology off of existing conservation laws and policies, the "why" of what we are hoping to achieve is already clear and accepted. 
- There is an existing user base. Rather than having to invest as much time and energy to grow the user base from zero, when a new tool is built to address the needs of an existing conservation policy program, it means there is already a strong potential user base to work with. Providing tools that improve the process of work already being done may be well received by users who are willing to adopt changes for efficiency, consistency, and other factors. This is not to understate the challenge of adoption that may exist, but rather to highlight the benefits of already having users ready to use a new technology.

- Easing technical scaling. While co-opting an existing user base can dramatically accelerate the social scaling of using a technology, the sizable workforce and geography the government manages necessitates an unprecedented technical scaling for the technologies used. This means that the tools used must be applicable across both different physical terrains and function for hundreds of people with varying technical expertise. This has been achieved with other technologies that the government uses and we simply want to highlight that new technologies should learn from and piggy-back on the government's current technical approaches while being mindful of where improvements are needed. There are also opportunities to leverage the significantly larger scale of government resources, or other combinations of public-private partnerships.

- Having flexible frameworks to guide adoption and use. Most conservation challenges manifest locally, such as habitat conversion, overexploitation, invasive species, and many forms of pollution; climate and other global process changes are exceptions. As such, to advance uptake of new tools, any guidance for adoption has to accommodate local considerations - external factors, cultural norms and history, and capacity. Existing governmental structures, from national offices to regional offices to field offices have already developed much of this know-how, so that technology developers don't have to start from scratch.

- Encouraging adaptive management with technology. Direct integration of legal and policy expertise and implementation with the technology development means better opportunities to integrate research and monitoring that feeds back into and improves the system. Adaptive management is a cornerstone of conservation (Walters \& Holling, 1990; Parma, 1999; McCarthy \& Possingham, 2007) and of any efficiency-improving process (Dreiss et al. 2017). Replicating this model within the software and hardware development process is crucial for its success. Informal and formal settings to give feedback (e.g., from online forums, workshops, or interactive websites) would foster a collaborative and informative partnership between policy implementers and technologists. This ultimately strengthens the product, builds trust among users and the platform, and results in better conservation technologies.

- Facilitating automated cross-program processes. While a specific technology may address one or a few specific choke points of conservation policy implementation, it will likely be just one piece of a 
larger program. Knowledge of the detailed pieces as well as the programmatic overview can provide critical opportunities for the integrated development of technologies that automate cross-program information sharing. Absent the detailed legal-policy program overview, there is a greater risk of technological development that occurs in silos and may not become fully operational in the long-run, or may add unnecessary costs and complications.

\section{Process of conservation technology coproduction}

How does this work in practice? Engagement and partnership among technologists, policy experts, regulatory staff and agencies should start early and continue through a broad, four-part process:

1. Begin with a clear and thorough understanding of the legal, regulatory, policy, and implementation requirements for conservation. These foundational issues set the terms of what must be done or what cannot be done, how actions may be done, resource requirements for taking actions, and soforth, and must be respected.

2. Identify choke points in the conservation law and policy framework and implementation process that are amenable to technological innovations. This is where conservation practitioners and technology developers articulate a shared understanding of the challenges and possible range of technology solutions.

3. Design and develop the technological tools to address implementation needs while respecting the specific legal bounds. While step 2 may identify several possible solutions, typically one of those goes into development.

4. Deploy, test, and refine the tools in an integrated fashion with the governmental agencies, their regulated/engaged communities, and the technology developers. This is variously called adaptive management or iterative development, and is fundamentally co-productive.

To illustrate this process, we give three examples that focus on part of the ESA (Box 1), the section 7 consultation process, that we believe are improving conservation implementation. We note that while we illustrate this through the lens of the ESA, the fundamental model of coproduction of conservation technology is broadly applicable. Whether the Clean Water Act, Migratory Bird Treaty Act, state wildlife laws, or work carried out by private parties without a particular legal nexus, the same core requirement of close involvement of the conservation experts with the technology developers is key. 


\section{Box 1. Endangered Species Act overview}

The Endangered Species Act (ESA) was passed by the U.S. Congress in 1973 with strong bipartisan support, an acknowledgement of the importance of wildlife species to the nation and a means to conserve them. Species may be listed under the ESA as threatened (likely to become endangered throughout all or a significant portion of their range in the foreseeable future) or endangered (endangered throughout all or a significant portion of their range). Listing, critical habitat designation, recovery planning, and related topics are covered under section 4 of the ESA. Once listed, species receive certain protections in the ESA. Section 5 addresses land acquisition in certain circumstances to conserve species, section 6 requires that state and federal governments cooperate, and section 8 describes the protections against trade as part of international engagement. Three additional sections warrant slightly more discussion.

First, the ESA requires federal agencies to use their authorities to help recover species (section 7(a)(1); e.g., Evansen et al. 2021) and ensure their actions are not likely to jeopardize the existence of listed species or destroy or adversely modify designated critical habitat (section 7(a)(2), e.g., Malcom and Li 2015, Evans et al. 2019). These are facilitated through consultation processes in which federal agencies engage with the U.S. Fish and Wildlife Service and NOAA Fisheries.

Second and related, under section 9 of the ESA, all parties are prohibited from "take" (meaning to harass, harm, pursue, hunt, shoot, wound, kill, trap, capture, or collect) of individuals of an endangered fish or wildlife species. A federal agency can receive exemption for such take that is incidental to otherwise legal activities through section 7 consultation. Incidental take for non-federal entities can be authorized through a section 10(a)(1)(B) permit associated with a Habitat Conservation Plan (HCP).

Because section 7(a)(2) consultation is most relevant to the case studies here, Figure 1 provides a highly simplified overview of the process and the relationship to the case studies. 


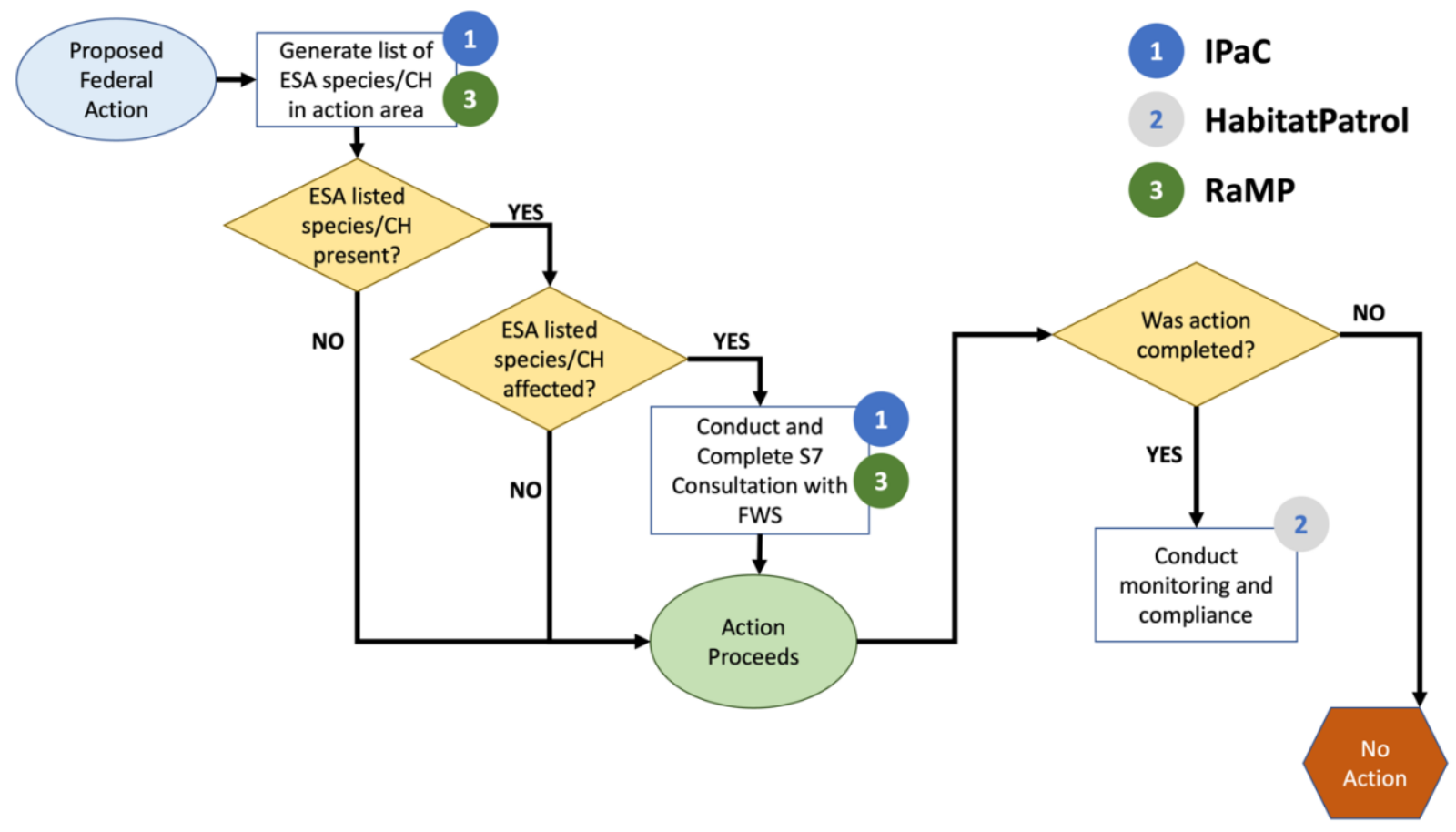

Figure 1. The three examples described in this article fit into particular parts of the ESA section 7 ("S7") consultation process, simplified here. ("CH" = critical habitat) Additional, relevant details are found in each case study account, and a full accounting of consultations can be found in USFWS (1998) and relevant implementing regulations cited therein.

- END BOX 1------

\section{Examples of conservation technology-policy coproduction}

In our roles in the non-governmental and governmental sectors, we have experience with three particular technology developments that illustrate conservation technology-policy coproduction. In each of these examples, the coproduction teams were assembled organically as conservation practitioners reached out to technology developers to discuss solutions.

\section{$\underline{I P a C: \text { Improving Endangered Species Act consultations }}$}

Our first example is the Information for Planning and Consultation (IPaC) system (https://ecos.fws.gov/ipac/), a technology coproduced by policy and technology staff within the U.S. Fish and Wildlife Service (FWS) to improve the efficiency, transparency, and consistency of implementing section 
7 of the ESA (Figure 1, circle 1). This part of the law governs interagency cooperation of federal agencies in implementing the ESA and is often considered the strongest yet most contentious part of the law (see Box 1)). $\mathrm{IPaC}$ development was driven by the need to meet the increased workload posed by the growing number of listed species and federal actions but stagnant funding for the ESA (see Malcom 2021).

IPaC development began in 2010 and was conceived, designed, and implemented around the section 7 consultation process (step 1 of the process proposed in this paper). The consultation process has evolved through extensive regulatory changes and court cases, such that the legal, regulatory, and policy requirements are very well-defined and very nuanced. As a result, any technological solutions have to account not just for feasibility and social acceptance, but bright legal lines that cannot be crossed.

The search for technology solutions to the section 7 consultation workload challenge began with the recognition of the choke points of the process (step 2). The data showed that large amounts of staff time were spent in three main areas: (a) generating lists of species that may be present within the area of a federal action (i.e., an action funded, permitted, or carried out by a federal agency) to be used by the agency to evaluate the potential effects of the action on a listed species or its critical habitat; (b) carrying out "informal consultation" to assist the federal agency in determining whether formal consultation is required and identify modifications to the action that the federal agency and applicant could implement to avoid the likelihood of adverse effects to listed species or critical habitat (>93\% of all FWS consultations; Malcom \& Li 2015); and (c) carrying out "formal consultation," to determine whether a federal agency's action is likely to jeopardize listed species or destroy or adversely modify critical habitat, which is $<7 \%$ of all consultations but generally the most time intensive per consultation. The first of these is readily automatable given adequate species range data and technology to allow user interaction with the data, i.e., drawing polygons of where an action and its effects will occur (Figure 1, circle 1, top left). Portions of the second and third choke points can be automated in cases where FWS can develop a programmatic consultation or internal analysis that can be delivered in IPaC via a "determination key" (Figure 1, circle 1, bottom center). Determination keys walk agency users through key questions based on the previously completed programmatic reviews to help them determine how species may be affected by the proposed project, and key geospatial questions are automatically answered. These answers result in a final consultation outcome that can be verified by FWS, as required or - if appropriate - help the action agency prepare for formal consultation. The second and third choke points are also minimized by helping federal agencies provide all information needed for the analysis up-front to avoid common delays in consultation. The back-and-forth communications to gather information missing from an initial consultation request can take months to years depending on the delay in review and response each time and the type of information needed. 
Development of IPaC started with a very limited staff designing basic tools to automatically generate species lists for federal actions and then grew to implement determination keys (step 3). Documents issued using these tools are then automatically logged into FWS's consultation tracking system, and the local field office is automatically notified that a document was issued on their behalf. IPaC was developed with close coordination between software developers and FWS policy experts and staff in multiple offices around the country. Rather than releasing a completed tool suite to all FWS staff at once, the individual modules of IPaC have been developed by first targeting the section 7 challenges of particular offices as pilot programs (step 4), then expanding and scaling them. This approach has allowed close testing and refining with real-world users who are implementing section 7. Further, this integrated approach has been exceptionally helpful for socializing staff in FWS and other agencies to the new technologies of IPaC and adapting the existing section 7 practitioner "user base" of section 7 to IPaC. The most recent application of this iterative approach of technology coproduction has been the launch in December 2020 of the "Consultation Package Builder," a module of IPaC that walks users step-by-step through building a thorough effects analysis to submit to FWS for consultation.

While development is ongoing, IPaC demonstrates how technology can be leveraged to improve consistency, predictability, transparency, and conservation outcomes in the ESA section 7 consultation process. With a current user base of over 50,000 users, on average, $\mathrm{IPaC}$ is used to generate 275 official species lists and 55 determination key outcomes daily. Further, these numbers have been consistently on the rise since the release of IPaC. Historically, users would have had to contact a field office, requiring FWS biologist time to review and $\log$ these documents and resulting in waiting time for the federal agencies. These tools alone provide significant time savings for both federal agencies and the FWS, and greatly improve consistency of both responses and data management and reporting, and the feedback from agencies has been exceedingly positive. For qualifying projects, action agencies have now gone from waiting weeks or months for a response to being able to complete consultation in a matter of hours, and FWS biologists can audit and review that consultation document in a matter of a few minutes with no data entry time. Translating this into exact time and/or cost savings is challenging for many reasons, but in talking with each field office about their workload and estimated time pre-IPaC for the products delivered on their behalf, we conservatively estimate that about 57,000 hours of FWS staff time was saved due to the 212,487 documents IPaC issued to our users and automatically logged on behalf of our field offices in the past two years.

\section{HabitatPatrol: Automated habitat change detection}

A second example is HabitatPatrol, found at https://conservationist.io/habitatpatrol, a technology created outside of government to address a key step in conservation policy implementation: monitoring and reporting (Trouwborst et al., 2017; Malcom et al., 2017; Evans \& Malcom, 2020; Evansen et al., 2021). Recognizing that 
current tools and resource limitations preclude regular, comprehensive monitoring of protected species habitats and thousands of conservation agreements (Evans \& Malcom 2020), the goal of HabitatPatrol is to enable spatially extensive monitoring in a cost-efficient manner, especially at the end-points of ESA consultation (Figure 1, circle 2).

The development of HabitatPatrol began with an understanding of how the status of listed species are assessed, and how conservation agreements are currently developed, implemented, and enforced (step 1). After years of experience working on ESA policy, HabitatPatrol developers were familiar with a variety of ESA provisions providing protections to listed species, including consultations under section 7 and habitat conservation plans under section 10 (ESA; 16 U.S.C. \$\$1531 et seq.; 5 ESA \$10, 16 U.S.C. \$1539), as well as the need for regular review of listed species' status (ESA s4(c)(2)). The developers' knowledge of these programs and professional relationships with FWS staff who have primary responsibility to implement the ESA meant that we also knew that monitoring and reporting have typically been under-resourced or absent entirely (U.S. Government Accountability Office 2009). Thus we identified these shortcomings as not only a key limitation to the effectiveness of two major conservation programs under the ESA, but one that could be improved with technology (step 2).

These needs and context informed the design and features of HabitatPatrol (step 3). The tool uses Sentinel-2 data, a choice informed by knowledge of the scale of features needed to be detected by enforcement agencies and budgetary limitations that place a premium on free data. Rapid detection of changes necessitated an algorithm that did not rely on trend analysis of long image time series. Finally, because FWS is responsible for protecting species in diverse habitats the tool needed to be applicable in the common habitat types found across the United States, therefore the algorithms of HabitatPatrol were developed to work flexibly in a variety of North American landscape contexts. The details of the algorithm and specific examples of its application are described by Evans and Malcom (2020). For example, the functionality has been useful in producing habitat loss data in non-forested ecosystems including the grasslands of the lower Great Plains (Evans \& Malcom 2020) and desert of the Permian basin (Malcom \& Moskwik, 2018). In both of these cases, output data directly contributed to listing decisions, illustrating the importance of both anticipating needs and awareness of current policy opportunities. At this time, efforts are underway to further develop nongovernmental partnerships for business scaling; in turn, this is expected to facilitate adoption of HabitatPatrol - or at least the underlying algorithms - by federal agencies such as FWS.

\section{Range and Mapping Protocol (RaMP): public-private collaboration}

Our third example is the product of public-private coproduction of conservation technology. Range and Mapping Protocol (RaMP) is an example of a tool developed to facilitate the refinement of official species 
range maps used in regulatory contexts by FWS. In particular, those range maps are important in section 7 for generating species lists (Figure 1, circle 3, top left) and as part of evaluating the effects of actions during consultation (Figure 1, circle 3, bottom center). Further, the range maps refined with RaMP have application with processes such as HCP development (see Box 1). Traditionally, official species range maps have been at the resolution of counties, but much greater precision is possible. However, the process of refining species' range maps is both a social and technical challenge because it can require the coordination and consensus of many biologists and program managers, which RaMP was designed to address.

The development of RaMP began with the recognition of the importance of range map precision in carrying out the ESA, in particular section 7 consultation (step 1). The official records of where listed species occur determine when and where regulations and policies under the ESA and other conservation laws are implemented. As a result, the accuracy and precision of the maps can have a large impact on the efficiency and effectiveness of these laws: inaccurate maps may trigger unnecessary expenditures by regulated entities and the FWS, or they may fail to provide protections for imperiled species. Through a series of public-private workshops (e.g., https://defenders-cci.org/events/workshops/refined-range-mapping/) and meetings, the policy guidance needs were identified (U.S. Fish and Wildlife Service 2019). From that process, an opportunity was identified for a web-based tool to facilitate collaborative mapping to speed the editing and adoption of new maps, and which could be integrated into FWS's technology infrastructure (step 2).

With the need identified, non-governmental partners (JWM and MJE) began the technology development of a collaborative mapping tool while staying in contact with FWS staff about their needs (step 3). A non-federal version of the tool, Collaborative Mapper, was launched to facilitate testing and refinement between the agency and the non-profit, and continues to be maintained

(https://conservationist.io/apps/collaborativemapper/home) (step 4). After extensive review and revision through an iterative process with FWS, the codebase was forked from Collaborative Mapper and on-boarded to FWS's own infrastructure, where the tool was named RaMP. It allows multiple users to dynamically upload data and propose edits to the same geospatial vector data without creating multiple copies of each file. The integrated technology-policy development means that RaMP achieves three essential needs: (1) Standardization of data used to create species range maps, including occurrence data; (2) the generation of unique metadata for all submitted data; (3) and it allows species experts to edit, vet, and submit data collaboratively. This functionality leads to greater consistency, transparency, accountability, and accessibility of data across FWS. Further, it has been our clearest example of how conservation technology coproduction can readily bridge the public-private spheres to produce useful conservation tools.

We summarize the three case studies - including the key law or policy issue, the limitation and solution that was identified, and the team the developed the solution - in Table 1. 
Table 1. Overview of the three case studies presented above.

\begin{tabular}{|c|c|c|c|}
\hline & $\mathrm{IPaC}$ & Habitat Patrol & RAMP \\
\hline Law/Policy & ESA section 7 & ESA sections $4,7,10$ & ESA sections 7,10 \\
\hline Limitation & $\begin{array}{l}\text { Time intensive for FWS } \\
\text { biologists to generate species } \\
\text { lists for proposed projects, log } \\
\text { required data for project } \\
\text { records, and conduct } \\
\text { consultation on all federal } \\
\text { actions for } \sim 1,600 \text { listed } \\
\text { species. }\end{array}$ & $\begin{array}{l}\text { Time and resource } \\
\text { intensive to perform } \\
\text { comprehensive } \\
\text { monitoring of all } \\
\text { protected habitats. }\end{array}$ & $\begin{array}{l}\text { Inaccurate maps of species } \\
\text { ranges create unnecessary } \\
\text { work for agency staff and } \\
\text { inadequate protection for } \\
\text { species. Updating maps } \\
\text { requires input and } \\
\text { coordination among many } \\
\text { staff. }\end{array}$ \\
\hline Solution & $\begin{array}{l}\text { Automate generation of species } \\
\text { lists, logging of project records, } \\
\text { and delivery of appropriate } \\
\text { programmatic consultations. } \\
\text { Interactively assist users with } \\
\text { creating thorough } \\
\text { documentation to submit for } \\
\text { consultation. }\end{array}$ & $\begin{array}{l}\text { Automate the passive } \\
\text { detection of land cover } \\
\text { changes using satellite } \\
\text { data. }\end{array}$ & $\begin{array}{l}\text { Enable collaborative } \\
\text { creation \& modification of } \\
\text { geospatial data by multiple } \\
\text { users. }\end{array}$ \\
\hline Team & $\begin{array}{l}\text { FWS policy staff, FWS } \\
\text { biologists, FWS developers }\end{array}$ & $\begin{array}{l}\text { NGO policy experts, } \\
\text { data scientists, and } \\
\text { developers }\end{array}$ & $\begin{array}{l}\text { FWS biologists, developers, } \\
\text { NGO data scientist and } \\
\text { developers }\end{array}$ \\
\hline
\end{tabular}

\section{Open questions for conservation technology coproduction}

While we believe that coproduction of conservation technologies is an ideal way to scale the impact of technology, we recognize that there are challenges in using technology to change or replace any current process. There are several aspects that must be considered to determine if technology is the best fit for a given policy, including conservation of the workforce, regulatory, or cultural shifts that are needed for conservation technology to be used efficiently. We have identified four outstanding questions for practitioners from the technology and law or policy sectors to answer in coming years: 
- Are there common conservation policy implementation processes that are choke-points-or missing entirely - and amenable to technological solutions? Not every aspect of conservation policy implementation is limited in ways that are amenable to technology solutions. Systematic evaluations of implementation of a variety of conservation laws and policies, from international to local, would likely highlight common patterns that could be addressed. This is not to suggest that identifying common patterns would remove the need for people with legal-policy expertise to be involved through technology development - the details matter a great deal and active partnership is required - but that such generalization may help identify new generalized solutions.

- What new policies, laws, or institutions might be needed to expand and promote the use of technology in conservation? There are likely many underused laws and policies that could be brought to bear on improving conservation technology adoption, such as the Open Government Data Act (United States Congress 2018) and implementing policies and procedures, including streamlined procurement processes. One of the most promising proposals from the federal side may be the idea of creating a "Digital Service for the Planet" (DSP; Environmental Policy Innovation Center et al., 2021), akin to the U.S. Digital Service created during the Obama administration (USDS, 2021). A DSP would address many of the core concerns of how the government uses technology for environmental applications, including conservation. The current lack of programmatically tailored technology staffing means that the White House and agency staff often rely on out-of-date information, operate in unnecessary silos, or suffer from an inability to collaborate due to an absence of common digital infrastructure. These are challenges that technology companies are continuously innovating around, as are governmental organizations like the U.S. Digital Service. There is a particularly timely opportunity for conservation because many relevant programs across different agencies have overlapping data and technology infrastructure needs, but operate largely without coordination. The primary goal of the DSP would be to enable agencies to quickly adopt proven, reliable, and best-available technology for planning, operating, and monitoring natural resource programs, while yielding the co-benefit of interagency collaboration.

- What are the social barriers to adopting new technologies for conservation? What role can leadership play in lowering barriers? Our experience is that technological capability is rarely the limiting factor to coproduction of conservation technology, and instead, a combination of social barriers and related organizational or institutional norms must be surmounted. This means changemanagement skills are key, such as building leadership buy-in to technological adoption, providing program staff training and confidence to embrace technology, and staffing technological positions within agencies, all within conservation program areas. In contrast, Chief Technology or Information Officers are often relegated to administrative or operational areas of an agency, such as finance and human resources, which introduces artificial barriers to adoption. Restructuring positions like these 
could be critical to adoption and integration of technology to support their programs where necessary, and they can more easily foster collaboration given common digital infrastructure needs across agencies. This shift in leadership could also be the signal needed for agency staff to feel more comfortable leveraging conservation technologies applicable to their programs.

A key clarification is that this does not mean that all agency staff need to be experts in technology development. Instead, they should have the training and support to know what tools can support their programs, have knowledgeable and accessible colleagues, and be empowered to leverage other partnerships when relevant. Formalizing processes to facilitate collaborations between agencies and outside organizations could be one way to achieve this - it is core to the concept of coproduction. These could mimic several forms popular in the technology and academic space, such as university research labs and other grant-funded organizations, which are familiar with Request For Proposal (RFP) announcements, and similar calls for specific technology could mobilize these partners. Workshops facilitated by agencies would be another means of developing effective collaborations around solutions to specific problems. Finally, significant advances have been achieved through open-source competitions and "hack-a-thons" in which solutions to specific technical challenges are crowd-sourced to the relevant technology community. Conservation focused equivalents have been organized (e.g., Conservation X Labs), and there is an opportunity for agencies to play a more active role in facilitating these for successful coproduction. This would require social and cultural shifts that could greatly advance the meaningful application of technology to conservation challenges.

- What are the resource barriers to adopting technology in conservation; are solutions available but cost-prohibitive; and how can technology lower the barrier? Scalable technology requires investment of resources for hardware and networking infrastructure, cloud computing resources or both. Additionally, these technologies often require dedicated staff with specialized skill sets that differ, necessitating the creation of new positions. In the non-governmental space, these barriers are often overcome in the form of grants and in-kind support from technology providers such as Microsoft and Google. For the government, it is essential that legislatures appropriate adequate funding for the transformation of departments, agencies, and their branches to effectively use - and coproduce - the tools that enable the successful implementation of conservation laws and policies.

\section{Conclusion}

The scale and scope of the biodiversity crisis requires transformative changes in how we - society broadly work to turn the tide. The development, dissemination, and adoption of new technologies can be one such transformative change, and to be most effective, we believe that coproduction of technology with existing 
conservation legal and policy structures is an approach that offers huge benefits. In each of the examples discussed, the successful application of technology to strengthen conservation policy was predicated on a deep understanding of chokepoints and limitations of current implementation. In implementation, this knowledge was born out of extensive ESA policy experience and professional relationships. While these assets are a fantastic starting point, relying on such specialized circumstances limits the diversity of perspectives and solutions. Workshops, RFPs, and hackathons developed and driven by agencies could be useful tools for expanding the pool of technology contributors, and improving the applicability of products. Whatever form, the key is that decision makers and technology developers collaborate closely to coproduce the next generation of technologies that conservation demands.

\section{Acknowledgements}

We thank the many partners in government, especially the U.S. Fish and Wildlife Service, without whose collaboration the ideas in this contribution would not be possible. We also thank \# reviewers whose feedback improved the manuscript. The findings and conclusions in this article are those of the author(s) and do not necessarily represent the views of the U.S. Fish and Wildlife Service.

\section{Literature Cited}

Beier, P., Hansen, L. J., Helbrecht, L., \& Behar, D. (2017). A How-to Guide for Coproduction of Actionable Science: Coproducing actionable science. Conservation Letters, 10(3), 288-296. https://doi.org/10.1111/conl.12300

Díaz, S., Zafra-Calvo, N., Purvis, A., Verburg, P. H., Obura, D., Leadley, P... Zanne, A. E. (2020). Set ambitious goals for biodiversity and sustainability. Science, 370(6515), 411-413. https://doi.org/10.1126/science.abe1530

Dinerstein, E. (2018). Fighting Illegal Poaching with a Purpose-Built AI Camera. Retrieved from: https://simplecore.intel.com/ai/wp-content/uploads/sites/69/Fighting_Illegal_Poaching-1.pdf

Dreiss, L. M., Hessenauer, J. M., Nathan, L. R., O’Connor, K. M., Liberati, M. R., Kloster, D. P., and Morzillo, A. T. (2017). Adaptive Management as an Effective Strategy: Interdisciplinary Perceptions for Natural Resources Management. Environmental Management, 59(2), 218-229. https://doi.org/10.1007/s00267-016-0785-0

Endangered Species Act, Section 7, no. ESA; 16 U.S.C. $\$ \$ 1531$ et seq. (1973).

Endangered Species Act, Section 10, no. ESA \$10, 16 U.S.C. \$1539 (1973).

Environmental Policy Innovation Center. (2021). Digital Service for the Planet. Retrieved from: http://policyinnovation.org/wp-content/uploads/Digital-Service-for-the-Planet-August-10-2021.pdf 
ESRI. (2021). ArcGIS. Retrieved from: https://www.esri.com/en-us/arcgis/products/arcgis-pro/overview

Evans, M. J., \& Malcom, J. W. (2020). Supporting habitat conservation with automated change detection in Google Earth Engine. Conservation Biology, 35(4), 1151-1161. https://doi.org/10.1111/cobi.13680

Evansen, M., Carter, A., \& Malcom, J. (2021). A monitoring policy framework for the United States

Endangered Species Act. Environmental Research Letters, 16(3), 031001. https://doi.org/10.1088/17489326/abe0ea

Germany. (2020). Sixth National Report. Convention on Biological Diversity. Retrieved from: https://chm.cbd.int/database/record?documentID $=250738$

Global Forest Watch. (2021). Forest Monitoring Designed for Action. Retrieved from: https://www.globalforestwatch.org/

Intergovernmental Science-Policy Platform for Biodiversity and Ecosystem Services, (IPBES). 2019. Global Assessment Report on Biodiversity and Ecosystem Services of the Intergovernmental Science-Policy Platform on Biodiversity and Ecosystem Services. Retrieved from: https://ipbes.net/global-assessment

Kenya. (2021). Sixth National Report. Convention on Biological Diversity. Retrieved from: https://chm.cbd.int/database/record?documentID=253902

Lahoz-Monfort, J. J., \& Magrath, M. J. L. (2021). A Comprehensive Overview of Technologies for Species and Habitat Monitoring and Conservation. BioScience, biab073.

https://doi.org/10.1093/biosci/biab073

Malcom, J., Kim, T., \& Li, Y.-W. (2017). Free Aerial Imagery as a Resource to Monitor Compliance with the Endangered Species Act [Preprint]. bioRxiv https://doi.org/10.1101/204750

Malcom, J. W., \& Li, Y.-W. (2015). Data contradict common perceptions about a controversial provision of the US Endangered Species Act. Proceedings of the National Academy of Sciences, 112(52), 15844-15849. https://doi.org/10.1073/pnas.1516938112

Malcom, J. W. (2021). “Consequences of Resource Limitations on ESA Implementation,” in Endangered Species Act, Third Edition, eds. D. C. Baur and Y.-W. Li (Washington, D.C.: American Bar Association), 417-437.

Malcom, J., and Moskwik, M. (2018). The Texas Conservation Plan has not slowed oil and gas well development in dunes sagebrush lizard habitat. doi:10.12688/f1000research.15346.1.

Marxan Conservation Solutions. (n.d.). Marxan Software. Retrieved from: https://marxansolutions.org/

McCarthy, M. A., \& Possingham, H. P. (2007). Active Adaptive Management for Conservation. Conservation Biology, 21(4), 956-963. https://doi.org/10.1111/j.1523-1739.2007.00677.x

McClure, C. J. W., Martinson, L., \& Allison, T. D. (2018). Automated monitoring for birds in flight: Proof of concept with eagles at a wind power facility. Biological Conservation, 224, 26-33. https://doi.org/10.1016/j.biocon.2018.04.041 
Palau. (2019). Sixth National Report. Convention on Biological Diversity. https://chm.cbd.int/database/record?documentID $=248613$

Parma, A. M. (1998). What can adaptive management do for our fish, forests, food, and biodiversity? Integrative Biology: Issues, News, and Reviews, 1(1), 16-26.

Pörtner, H. O., Scholes, R. J., Agard, J., Archer, E., Bai, X., Barnes, D., .. Ngo, H. (2021). IPBES-IPCC cosponsored workshop report on biodiversity and climate change (Version 2). Zenodo. https://doi.org/10.5281/ZENODO.4782538

Secretariat of the Convention on Biological Diversity. (2020). Global Biodiversity Outlook 5. Retrieved at: https://www.cbd.int/gbo5

SMART (n.d.). SMART 7. Retrieved from: https://smartconservationtools.org/Download/SMART-7Release

Speaker, T., O’Donnell, S., Wittemyer, G., Bruyere, B., Loucks, C., Dancer, A., et al. (2021). A global community-sourced assessment of the state of conservation technology. Conservation Biology Ahead of Press. doi:10.1111/cobi.13871.

Trouwborst, A., Blackmore, A., Boitani, L., Bowman, M., Caddell, R., Chapron, G., ... Linnell, J. D. C. (2017). International Wildlife Law: Understanding and Enhancing Its Role in Conservation. BioScience, 67(9), 784-790. https://doi.org/10.1093/biosci/bix086

Turnhout, E., Metze, T., Wyborn, C., Klenk, N., \& Louder, E. (2020). The politics of co-production: Participation, power, and transformation. Current Opinion in Environmental Sustainability, 42, 15-21. https://doi.org/10.1016/i.cosust.2019.11.009

United States Digital Service. (2021). https://www.usds.gov/

US Fish and Wildlife Service. (2019). Standard Operating Procedure: USFWS refined range maps for threatened and endangered species. Washington, D.C. Moskwik, M., Mainali, K., Pavelka, M., Nicolaysen, T., Juliusson, L., Chhetri, D., et al., editors. Available at: https://ecos.fws.gov/docs/SR SOP/SDM SOP Final.pdf.

U.S. Government Accountability Office. (2009). Performance \& Accountability Report. Retrieved from: https://www.gao.gov/products/gao-10-234sp

United States Congress. (2018). Open Government Data Act, no. Title II H.R. 4174

Walters, C. J., \& Holling, C. S. (1990). Large-Scale Management Experiments and Learning by Doing. Ecology, 71(6), 2060-2068. https://doi.org/10.2307/1938620

World Wildlife Fund (WWF). (2020). Living Planet Report 2020 - Bending the curve of biodiversity loss. Retrieved from: https://www.zsl.org/sites/default/files/LPR\%202020\%20Full\%20report.pdf 